\title{
Cidadania e direitos sexuais na África do Sul: reflexões sobre o reconhecimento legal das uniões entre pessoas do mesmo sexo
}

\author{
Gustavo Gomes da Costa Santos \\ Doutor em Ciência Política (Universidade Estadual de Campinas) \\ Professor da Universidade Federal de Pernambuco \\ gustavo.gomesdacosta@yahoo.com.br
}

\begin{abstract}
Resumo O presente artigo analisa a trajetória de construção de direitos sexuais relativos à conjugalidade de casais do mesmo sexo na África do Sul. Tendo por base os achados da pesquisa de doutorado, intitulada Cidadania e direitos sexuais: um estudo comparativo do reconhecimento legal das uniões entre pessoas do mesmo sexo no Brasil e na África do Sul, o texto refletirá sobre a forma como ativistas gays e lésbicas idealizaram e colocaram em prática a luta pelo reconhecimento legal dos casais do mesmo sexo naquele país. Analisar-se-á o contexto social e político do país, com ênfase no momento de transição para o regime de maioria negra, juntamente com as estratégias de ação de ativistas gays e lésbicas, seus principais opositores e os resultados, intencionais ou não, de suas mobilizações em termos de ganhos legais.
\end{abstract}

Palavras-chave: cidadania, direitos sexuais, uniões entre pessoas do mesmo sexo, reconhecimento legal, África do Sul.

A questão do reconhecimento legal das uniões homosse$\mathrm{A}_{\text {xuais assume, atualmente, caráter transnacional. Em diversos }}$ países das mais variadas culturas e nos mais diferentes arranjos institucionais, encontramos ativistas $\mathrm{LGBT}^{1}$ lutando pelo reconhecimento legal das uniões entre pessoas do mesmo sexo. De um lado, ativistas LGBT afirmam a igualdade entre homossexuais e heterossexuais e a necessidade do Estado estender os direitos conjugais previstos no casamento aos casais do mesmo sexo. Do outro, grupos religiosos reafirmam o caráter "pecaminoso" e "antinatural" da homossexualidade e a procriação como objetivo primordial do casamento e da família. Assim, o casamento se restringiria necessariamente à união entre "um homem e uma mulher".

Ao lado de diversas nações europeias e latino-americanas, a África do Sul configura-se como importante exemplo de avanço no reconhecimento legal das uniões entre pessoas do mesmo sexo. Após o fim do regime de segregação racial conhecido como apartheid, o país foi o primeiro no mundo a proibir, expressamente em sua constituição, a discriminação por orientação sexual. Essa vitória legal possibilitou a 
ativistas gays e lésbicas acionar o poder judiciário com vista à revogação de leis discriminatórias e à garantia de direitos aos casais homossexuais. Em 2006, o país foi o primeiro do hemisfério Sul a aprovar uma lei nacional que reconheceu as uniões entre pessoas do mesmo sexo.

No que se refere à defesa dos direitos sexuais, a África do Sul constitui exceção no continente africano. A maioria das nações africanas criminaliza relações sexuais consensuais entre pessoas do mesmo sexo. Além disso, muitos líderes políticos no continente têm feito uso de claro discurso homofóbico, considerando a homossexualidade como algo alheio à cultura africana. Esses líderes - a exemplo do presidente do Zimbábue, Robert Mugabe, e do ex-presidente da Namíbia, Sam Nujoma (1990-2005) - afirmam ser a homossexualidade algo trazido para a África pelas antigas potências coloniais ocidentais, representando grande perigo para a integridade cultural de seus países (Phillips, 1997). No atual contexto de ineficientes respostas governamentais à expansão da epidemia de Aids no continente, a homossexualidade converteu-se facilmente em "bode expiatório" para todos os males que afetam a população (Long, 2003). Ativistas lésbicas e gays em África enfrentam crescente assédio das autoridades de seus países. Recentemente, parlamentares de Uganda apresentaram projeto de lei que, se aprovado, irá reforçar a penalização das práticas sexuais entre pessoas do mesmo sexo, a serem punidos, com a pena de morte, indivíduos portadores do vírus HIV que mantiverem relações sexuais consensuais com outra pessoa do mesmo sexo (BBC News, 2009).

No presente artigo, analiso a trajetória sul-africana de construção de direitos sexuais relativos à conjugalidade de casais homossexuais. A ênfase do texto recairá na reflexão sobre a maneira como ativistas gays e lésbicas idealizaram e colocaram em prática a luta pelo reconhecimento legal das uniões entre pessoas do mesmo sexo. Para tanto, analiso o contexto social e político do país, principalmente no momento de transição para o regime de maioria negra, enfatizando suas estratégias de ação, seus principais opositores e os resultados, intencionais ou não, de suas mobilizações em termos de ganhos legais. $\mathrm{O}$ artigo tem por base os achados da minha pesquisa de doutorado em Ciência Política, realizada na Unicamp.

O artigo terá a seguinte estrutura. Primeiramente, farei sucinto resgate do debate acadêmico e político acerca das reivindicações em torno do casamento gay. Posteriormente, apresentarei breve histórico das mobilizações de gays e lésbicas na África do Sul, ocorridas no bojo das transformações políticas vivenciadas por aquele país após a década de 1980. Em seguida, analisarei a reivindicação pela inclusão do termo "orientação sexual" na cláusula antidiscriminatória da nova constituição e a batalha judicial para garantia de direitos conjugais aos casais do mesmo sexo, que culminou com a aprovação da Lei de União Civil em 2006.

\section{As reivindicações pelo reconhecimento legal das uniões entre pessoas do mesmo sexo: 0 debate teórico}

É difícil estabelecer, com precisão, o momento em que a discussão sobre conjugalidade de gays e lésbicas emergiu no ativismo homossexual em nível mundial. Nos seus primórdios, o movimento de liberação gay lutava pela afirmação de uma identidade homossexual, contrária aos discursos médico-legais que associavam a homossexualidade a uma suposta "patologia" ou "transtorno sexual". Pregava-se a liberação da sexualidade e criticava-se o machismo e o sexismo existente na cultura e nas relações sociais (Engel, 2001 e MacRae, 1990). A ênfase da luta homossexual estava em questionar os padrões socialmente definidos, não só com referência à sexualidade, mas também concernente aos arranjos afetivos conjugais (principalmente uma crítica feroz à monogamia).

Na década de 1980, com o advento da Aids e a morte de vários ativistas, o movimento homossexual experimentou mudança radical no seu foco de ação em vários contextos nacionais, passando a trabalhar de forma intensiva em campanhas de prevenção à doença junto à comunidade homossexual. No auge da epidemia, as campanhas de prevenção reforçavam que relações sexuais com múltiplos parceiros aumentavam o risco de contágio pelo vírus HIV. Isso pode explicar a razão de muitos homossexuais buscarem relacionamentos monogâmicos e estáveis como uma forma de proteção contra a doença. Nesse sentido, é provável que a Aids tenha tido impacto decisivo na importância que as demandas por direitos concernentes à conjugalidade homossexual obtiveram no movimento homossexual dos últimos anos.

O tema da garantia de direitos aos casais do mesmo sexo ganhou projeção mundial quando a Suprema Corte do estado norte-americano do Havaí, em 1993, chegou a um veredito que abria a possibilidade de reconhecimento legal desses casais pela lei (Fassin, 2001 e Chauncey, 2004). Desde então, a questão dos same-sexmarriages passou a povoar constantemente os debates da opinião pública por todo o mundo. Vários países europeus aprovaram legislações que reconheciam a legitimidade desses casais e garantiam direitos patrimoniais, mas em sua maioria, ainda vetavam a adoção de crianças (Kitzinger e Wilkinson, 2004). 
A reivindicação pela aprovação do casamento gay passou, então, a ocupar lugar de destaque na agenda de demandas do ativismo gay e lésbico em vários países, suscitando intenso debate acadêmico e político acerca do tema. Ao analisar as discussões em torno da aprovação do Pacto Civil de Solidariedade (Pacs) na França, Judith Butler (2003) identificou que seus opositores "naturalizaram" a noção de cultura e de parentesco, afirmando - por meio de referências ao complexo de Édipo, de Freud, e ao tabu do incesto, de Lévi-Strauss - a diferença entre os sexos biológicos como ponto fundacional da cultura. Butler refuta esse argumento, demonstrando que, em várias civilizações, a definição do parentesco não estaria necessariamente vinculada ao tabu do incesto. A definição do parentesco, como exclusivamente heterossexual, vincular-se-ia à tentativa de manutenção de uma suposta "cultura francesa", figurando como uma nova forma de racismo (Butler, 2003).

Outra crítica da autora diz respeito aos "perigos" de se defender, de forma acrítica, o casamento gay. Por um lado, a defesa do reconhecimento de uniões entre pessoas do mesmo sexo acabaria por reiterar a legitimidade do casamento em detrimento de outros arranjos afetivo-conjugais possíveis, o que significaria restringir o reconhecimento legal a uniões que se assemelham ao casamento. Por outro, a defesa do casamento gay tornaria uma discriminação coletiva contra os homossexuais em uma discriminação seletiva contra aqueles homossexuais que não se encaixassem no padrão legalmente sancionado de arranjo conjugal (relação monogâmica). Essas críticas não levam a autora a negar a importância de garantir direitos aos casais homossexuais e aí residiria o "dilema" do casamento gay.

Outro argumento presente no debate sobre conjugalidadede gays e lésbicas defende a aprovação do casamento, e não de outras formas de reconhecimento (parceria civil ou união civil), como forma de garantia plena de direitos para casais do mesmo sexo. Kitzinger e Wilkinson (2004) demonstram que o não reconhecimento das uniões entre pessoas do mesmo sexo enquanto casamento - mesmo quando a lei garante todos os direitos concernentes ao casal heterossexual, inclusive a adoção de crianças - acaba por reproduzir a ideia de um status inferiorizado das uniões homossexuais em relação às heterossexuais. A diferença na nomenclatura funcionaria como forma de exclusão de gays e lésbicas, ao garantir a eles uma "cidadania de segunda classe" e reproduzir o princípio de "iguais, mas separados" que sustentou por anos a opressão de negros em países tão diversos como EUA e África do Sul.

Observa-se que a questão da nomenclatura conferida legalmente às uniões entre pessoas homossexuais tem grande relevância, na medida em que expõe duas facetas importantes da questão do reconhecimento legal dos casais do mesmo sexo. A primeira delas refere-se à garantia, ou não, a esses casais, dos mesmos direitos conjugais previstos aos casais do sexo oposto (direito à herança, à declaração conjunta de bens, à adoção conjunta, à garantia de visto de permanência ao parceiro estrangeiro etc.). A outra face refere-se à equiparação "simbólica", ou não, no âmbito da lei, entre casais homossexuais e heterossexuais.

$\mathrm{Na}$ ocasião dos debates no Parlamento da África do Sul acerca do reconhecimento das uniões entre pessoas do mesmo sexo em 2006, houve grande polêmica a respeito de como nomear legalmente essas uniões. A decisão da Corte Constitucional, que exortara a regulamentação da matéria, deixou a critério do Legislativo nomear tais uniões. Ativistas e defensores dos direitos LGBT exigiam a alteração da Lei do Casamento (Marriage Act, 1961), de forma a equiparar, no plano jurídico e simbólico, as uniões homossexuais às suas congêneres heterossexuais. Contudo, diversos grupos, tanto na sociedade civil quanto no Parlamento, opuseram-se à modificação da Lei do Casamento (Marriage $A c t$ ), o que levou à aprovação uma lei distinta de União Civil (Civil Union Act) que garante os mesmos direitos, previstos na Lei do Casamento, aos casais do mesmo sexo. A Civil Union Act abriu a possibilidade dos casais definirem como desejam nomear suas uniões (se casamento ou parceria civil), além de prever que tanto casais homossexuais como heterossexuais podem oficializar seus laços conjugais. Analisarei essa questão adiante de forma mais pormenorizada.

\section{Do apartheid à "nação arco-íris": breve histórico das mobilizações homossexuais na África do Sul}

A origem da mobilização em torno da questão da livre orientação sexual na África do Sul pode ser datada da década de 1960. Na época, observou-se, nas grandes cidades, a emergência de uma subcultura gay, com bares e casas noturnas voltados ao público homossexual, em sua maioria do sexo masculino, onde se podia vivenciar a homossexualidade de forma relativamente livre na conservadora e moralista sociedade sul-africana (Gevisser, 1995).

A visibilidade dessa subcultura gay acabou atraindo a atenção de membros do Partido Nacional (NP), implementadores das políticas de apartheid, que viam a homossexualidade como um "perigo" para a pureza racial do volk africâner e, assim, propuseram o endurecimento da legislação penal contra a homossexualidade. Como consequência, diversos homossexuais 
fundaram, em 1968, o grupo Homosexual Law Reform, considerado como a primeira iniciativa de organização dos homossexuais no país. Formado majoritariamente por gays, brancos e de classe média, o grupo adotou postura discreta de reivindicação, de maneira a angariar apoio de possíveis simpatizantes da causa homossexual dentro do NP, sem necessariamente se questionar o status quo. A iniciativa do Law Reform não conseguiu revogar a legislação penal contrária à homossexualidade, mas evitou que houvesse maior endurecimento da legislação existente (Gevisser, 1995).

É na década de 1980 que encontraremos o princípio de formação de um ativismo homossexual na África do Sul. No contexto de abrandamento da repressão e das reformas políticas promovidas pelo presidente P. W. Botha (Thompson, 2001), formou-se, em 1982, a Associação Gay da África do Sul (GASA) que propunha agregar os homossexuais, promovendo espaços de sociabilidade e garantindo serviços de apoio e aconselhamento. Com a presença predominante de gays brancos de classe média e uma postura claramente conservadora e apolítica, o grupo evitou vincular suas atividades ao movimento de liberação da maioria negra. A presença de negros entre eles era malvista por muitos membros e tinha apenas o intuito de demonstrar, internacionalmente, um suposto caráter não racista da associação. A prisão, em 1986, do ativista negro Simon Nkoli, membro do grupo, acabou expondo as contradições internas da GASA. A reticência da associação em condenar a prisão de Nkoli acabou levando, no mesmo ano, à expulsão do grupo da Associação Internacional de Lésbicas e Gays (ILGA).

A prisão de Nkoli também serviu de pretexto para setores progressistas do movimento internacional antiapartheid introduzirem o tema dos direitos gays no Congresso Nacional Africano (ANC), principal organização de resistência ao regime racista, banida pelo governo nacionalista em 1960 (Gevisser, 1995 e Hoad, Martin e Reid, 2005). Em entrevista à imprensa gay britânica em 1987, a representante do ANC no Reino Unido, Ruth Mompati, afirmou que o partido não possuía uma política direcionada a gays e lésbicas, pois isso significaria desviar o foco do ANC da luta geral pelo fim do apartheid. Para ela, os homossexuais não seriam "normais" e não precisariam de direitos, já que viveriam bem economicamente. As declarações de Mompati acabaram por forçar o ANC a se posicionar publicamente sobre o tema. Em novembro de 1987, o diretor de informação da organização, Thabo Mbeki, ${ }^{2}$ minimizou as declarações de seus companheiros e afirmou o comprometimento do partido com a garantia dos direitos de gays e lésbicas na nova África do Sul (Hoad, Martin e Reid, 2005).
Após o colapso da GASA em 1986, duas frentes de militância homossexual foram abertas na África do Sul. Uma delas, representada pelo Fundo para a Reforma Legal Nacional (NLRF), tentou repetir o modelo conservador de mobilização empregado pelo Law Reform e pela GASA, focando suas atividades especificamente em prol de reformas das leis contrárias aos homossexuais, sem envolver-se na luta pelo fim do apartheid. Já a outra frente tentou vincular a luta homossexual às reivindicações mais amplas pela democratização e pelo fim do apartheid. A formação de novos grupos - Gays e Lésbicas do Witwatersrand (GLOW), em 1988, com a participação predominante de ativistas negros, sob a liderança de Simon Nkoli; e a Organização de Ativistas Gays e Lésbicas (OLGA), em 1987, com a participação expressiva de ativistas brancos e intelectuais de classe média, engajados na luta antiapartheid - aponta para a mudança no perfil da mobilização homossexual. Em um momento de aumento expressivo das revoltas populares contra o regime de segregação racial e o consequente recrudescimento da repressão estatal contra o movimento de liberação negra (Guiliomee e Mbenga, 2007), ambos os grupos vincularam-se à Frente Democrática Unida (UDF) que congregava várias organizações de oposição ao regime da minoria branca e alinhava-se ao ANC, na época atuando na clandestinidade. Em 1990, com a legalização do ANC e a subsequente libertação de Nelson Mandela, inaugurou-se o processo de democratização do país. No mesmo ano, foi organizada, pelo GLOW, a primeira Marcha do Orgulho de Gays e Lésbicas que aconteceu em Johanesburgo e contou com a presença de 800 participantes (Gevisser, 1995).

Nesse contexto de abertura política, grupos homossexuais passaram a reivindicar a inclusão da luta homossexual no discurso mais amplo da luta pelos direitos humanos. A partir daí, promoveram um intenso trabalho junto às lideranças do ANC para que a proibição de discriminação, em razão da orientação sexual, fosse incluída na Declaração de Direitos (Bill of Rights) organizada pelo partido e que serviria, posteriormente, para a confecção da nova constituição (Croucher, 2002). Embora muitos líderes e membros do ANC considerassem a homossexualidade anormal e alheia à cultura africana (Gevisser, 1995), o contato de várias lideranças do ANC, exiladas no exterior, com ativistas do movimento de liberação gay e a participação de ativistas homossexuais nas mobilizações antiapartheid contribuíram para o sucesso desse trabalho, tornando o ANC, em 1992, o primeiro partido africano a reconhecer formalmente o direito de gays e lésbicas (Fine e Nicol, 1995 e Croucher, 2002).

Após essa conquista, ativistas homossexuais prosseguiram no trabalho de lobby junto a outros partidos 
políticos e 43 organizações de todo o país se uniram, em 1994, para formar a Coalizão Nacional pela Equidade de Gays e Lésbicas (NCGLE). Essa frente passou a atuar junto à Assembleia Constitucional, a fim de garantir a manutenção, no texto final, da proibição de discriminação em razão da orientação sexual, o que ocorreu em 1996 e tornou a África do Sul o primeiro país no mundo a proteger formalmente os direitos dos homossexuais (Croucher, 2002).

Desde então, a NCGLE iniciou, junto aos tribunais, intenso trabalho de contestação da legislação existente, contrária aos homossexuais (Louw, 2005). Baseada nos ensinamentos do jurista e ativista antiapartheid Edwin Cameron, a NCGLE formulou estratégia de atuação na política institucional que ficou conhecida como "lista de compras". A lista consistia de reivindicações que seriam supostamente mais fáceis de serem alcançadas, como a garantia da mesma idade de consentimento para jovens gays e heterossexuais e a revogação da lei antissodomia, seguida das demandas potencialmente mais controversas, como casamento e adoção por casais do mesmo sexo (Berger, 2008). Mais ainda, a estratégia estabelecia que os ganhos jurídicos alcançados em um caso seriam utilizados para sustentar outras demandas de gays e lésbicas.

A primeira atuação da NCGLE no questionamento judicial de leis discriminatórias contra práticas sexuais consensuais entre adultos do mesmo sexo ocorreu após um prisioneiro ter sido enquadrado, em 1997, no crime de sodomia. A NCGLE questionou a constitucionalidade da lei, levando o caso à Corte Constitucional. Esta declarou a seção 20-A da Lei de Crimes Sexuais (Sexual Offences Act, 1957) inconstitucional, na medida em que o crime de sodomia contrariava o princípio da lei que proibia a discriminação por orientação sexual. Segundo o entendimento dos juízes da Corte, o tal crime não teria outro objetivo senão o de criminalizar uma prática sexual, vista como imoral e pecaminosa por parte da sociedade; além disso, reforçava os preconceitos existentes contra os homossexuais, colocando-os em uma situação de maior vulnerabilidade. A decisão da Corte foi fundamental para a consolidação da aplicabilidade do princípio da equidade entre homossexuais e heterossexuais previsto na constituição.

\section{Dos tribunais ao Parlamento: a trajetória de reconhecimento legal das uniões entre pessoas do mesmo sexo na África do Sul}

A questão do reconhecimento legal dos casais do mesmo sexo passou a constar da agenda de mobilização de ativistas LGBT por volta do ano de 1997. Durante os debates sobre a inclusão do termo "orientação sexual" na constituição entre 1994 e 1996, a questão do casamento gay foi conscientemente "evitada" pelos ativistas LGBT. Juntamente com temas como adoção e a presença de gays assumidos no exército, o reconhecimento legal dos casais do mesmo sexo foi deixado de lado por tratar-se, na avaliação dos membros da NCGLE, de tema polêmico e que poderia, de forma potencial, dividir a militância LGBT. Havia o receio de que trazer à tona esse debate poderia resultar na reação de grupos conservadores e na perda do apoio de setores do ANC. ${ }^{3}$ É importante salientar que em 1996 o NP, que na época fazia parte do Governo de Unidade Nacional, apoiou a inclusão do termo "orientação sexual", com a ressalva de que isso não implicasse na aprovação do casamento gay. ${ }^{4}$

Uma vez confirmada a manutenção do termo "orientação sexual" na versão final da constituição, a NCGLE organizou, em 1997 e 1998, diversos eventos junto à militância LGBT, para discutir a maneira de abordar o tema dos direitos de casais do mesmo sexo. Chegou-se à conclusão de que o momento ainda não era propício para trazer o tema à opinião pública, em virtude da proximidade da segunda eleição democrática no país em $1999 .{ }^{5}$ Havia o receio de que o tema "casamento gay" fosse politizado na disputa eleitoral, trazendo consequências desastrosas para o ativismo LGBT.

Apesar das reticências da NCGLE em trazer o tema para a opinião pública, diversos casais homossexuais iniciaram ação de litígio contra o Departamento de Assuntos Internos, ${ }^{6}$ almejando garantir aos seus parceiros o direito ao visto de permanência no país. A legislação sul-africana referente a estrangeiros (Aliens Control Act, 1991) previa um tipo especial de autorização para indivíduos casados com cidadãos sul-africanos. A demanda era estender esses direitos aos casais do mesmo sexo. A NCGLE iniciou lobby junto ao Departamento de Assuntos Internos e logrou obter de seu diretor-geral um acordo para estender os

\footnotetext{
3. "We must claim our citizenship" - report of the interim executive committee (IEC) of the National Coalition for Gay and Lesbian Equality, dez. 1995

4. Entrevista Jan, 22.9.2009. Os nomes dos entrevistados foram alterados, de forma a manter o sigilo de suas identidades.

5. Gauteng Public Workshop, "Recognise our relationships", NCGLE, 11.6.1998.

6. Department of Home Affairs.
} 
vistos aos companheiros do mesmo sexo dos litigantes até que o assunto fosse regulamentado pelo Parlamento. Todavia, em uma carta de janeiro de 1998 (Berger, 2008), o mesmo diretor-geral voltou atrás e cancelou a concessão, já que na sua ótica, o pedido de visto de permanência para casais do mesmo sexo não se incluiria nas circunstâncias especiais previstas na legislação.

Esse fato acabou por precipitar a ida do tema para a Corte Superior do Cabo. Após diversos recursos impetrados pelo Departamento de Assuntos Internos, o caso chegou à Corte Constitucional. Em decisão de 1999, a Corte julgou que a seção 25 (5) do Aliens Control Act visava proteger o direito dos parceiros sul-africanos de constituir uma família com seus parceiros estrangeiros. Gays e lésbicas teriam a mesma capacidade que seus homônimos heterossexuais de construir relações de caráter conjugal e familiar. Sendo assim, a lei era discriminatória na medida em que não estendia aos homossexuais sul-africanos o direito de seus parceiros do mesmo sexo obter o visto de permanência no país. A Corte decidiu então por incluir (read in) na seção 25 (5) da lei a expressão "ou parceiro do mesmo sexo em união não eventual" " após o termo "cônjuge".

A decisão de 1999 serviu de base legal para outras demandas judiciais que versavam sobre variados temas, como extensão de pensões a parceiros do mesmo sexo, ${ }^{8}$ indenização por morte de companheiro do mesmo sexo, ${ }^{9}$ adoção conjunta ${ }^{10}$ e direitos parentais. ${ }^{11}$ Essas decisões culminaram no julgamento da Corte Constitucional de $2005^{12}$ que declarou a definição de casamento - presente na Common Law e na Lei do Casamento (Marriage Act, 1961) - inconstitucional, já que não permitia aos casais formados por pessoas do mesmo sexo desfrutar "do mesmo status, direitos e responsabilidades" disponíveis aos casais heterossexuais. A Corte Constitucional exortou o Parlamento, em um prazo máximo de doze meses, a corrigir o defeito de constitucionalidade, de forma a garantir aos casais do mesmo sexo os benefícios tangíveis e intangíveis da figura institucional do casamento. É importante notar que a Corte Constitucional deixou ao Parlamento a incumbência de escolher a maneira de "corrigir" o problema. A Corte, porém, foi clara ao afirmar que qualquer que fosse a decisão do Parlamento, essa deveria garantir aos casais do mesmo sexo os mesmos "status, direitos e responsabilidades" frente aos seus homônimos heterossexuais.

Seguindo as determinações da Corte Constitucional, a Comissão Parlamentar Permanente de Assuntos Internos ${ }^{13}$ do Parlamento sul-africano apresentou, em setembro de 2006, projeto de lei de União Civil (Civil Union Bill), criando a figura jurídica da parceria civil (civil partnership) e garantindo aos casais do mesmo sexo os mesmos direitos previstos na legislação aos casais heterossexuais via casamento. Juntamente com a apresentação do projeto de lei, o Parlamento iniciou um amplo processo de consulta popular a respeito do tema. Foram realizadas audiências públicas nas nove províncias do país. ${ }^{14} \mathrm{O}$ primeiro fato relevante dessas audiências foi o amplo coro de vozes contrárias à lei, tanto de setores favoráveis quanto daqueles opositores aos direitos LGBT. Os primeiros afirmavam que a lei criava uma situação de "iguais, mas separados", já que previa novo instituto jurídico (a parceria civil), restrito apenas aos casais do mesmo sexo. Isso seria reproduzir o ideal de apartheid entre os casais heterossexuais e homossexuais. Para eles, a decisão da Corte Constitucional teria sido clara, quando afirmava que era necessário estender os benefícios tangíveis e intangíveis do casamento aos casais do mesmo sexo. Isso só seria possível por meio da alteração da Lei do Casamento. Qualquer outra forma de reconhecer legalmente os casais do mesmo sexo não estaria de acordo com os desígnios da Corte Constitucional.

Já entre os opositores dos direitos de LGBT, o projeto de lei gerou diversas inquietações. Os argumentos de cunho religioso e cristão dominaram as razões levantadas para a não aprovação da lei por parte dos setores conservadores na África do Sul. A condenação, por parte da Bíblia, da homossexualidade como comportamento pecaminoso e imoral foi amplamente utilizada por indivíduos e grupos religiosos para desqualificar o projeto. Nesse argumento, 7. No original "or partner, in a permanent same-sex life partnership". Vide NCGLE and others v Minister of Home Affairs, Constitutional Court
(CC) case 10/99, paragraph [98].

8. Satchwell v President of South Africa and Another, CC case48/2002.

9. Du Plessis v Road Accident Fund, Supreme Court of Appeal (SCA) case 359/2004.

10. Du Toit and De Vos v Minister of Welfare and Population Development and others, CC case40/2001.

11. J and Another v Director General, Department of Home Affairs, and others, CC 46/2002.

12. Fourie et al. v. Minister of Home Affairs, CC case 10/2005.

13. Parliamentary Portfolio Committee on Home Affairs.

14. Realizadas entre os meses de setembro e outubro de 2006, as audiências contaram com a presença da população em geral e de grupos organizados da sociedade civil (principalmente grupos religiosos, ativistas homossexuais e lideranças locais). Nas audiências, oficiais do Departamento de Assuntos Internos apresentaram todos os artigos da lei nas línguas locais, além do inglês. Também foram disponibilizados tradutores para que a população participasse no processo de input da lei, a despeito do não conhecimento da língua inglesa. 
o casamento era visto como uma instituição sagrada que teria por principal objetivo a procriação, só podendo existir entre um homem e uma mulher. Alterar a definição de casamento para incluir os casais homossexuais significaria a destruição de uma instituição sagrada e milenar, com possíveis consequências desastrosas para toda a sociedade. Os direitos das crianças a terem "um pai e uma mãe" e os possíveis efeitos perversos na identidade individual de crianças criadas por pais homossexuais também foram amplamente utilizados para fundamentar a rejeição ao projeto de lei.

É interessante notar que argumentos de cunho religioso/cristão são recorrentes nos debates acerca do reconhecimento legal das uniões entre pessoas do mesmo sexo, em países tão diversos como EUA, Espanha, Brasil e África do Sul. No entanto, nesse último, a questão da suposta "ausência" da homossexualidade na cultura africana foi também fartamente utilizada, em especial por líderes tradicionais locais, para justificar a rejeição da Civil Union Bill. Para os defensores desse argumento - que se assemelhava àquele apregoado por outros líderes africanos, a exemplo do presidente do Zimbábue, Robert Mugabe -, a homossexualidade seria algo não africano (unAfrican), importado e forçosamente imposto no país pelos colonizadores brancos europeus, ao longo dos séculos XIX e XX. Reconhecer o casamento entre pessoas do mesmo sexo seria totalmente contrário à moral e aos valores da cultura africana, supostamente baseada na família nuclear, composta por um pai, uma mãe e sua prole. Legalizar o casamento entre pessoas do mesmo sexo, na ótica de vários indivíduos e lideranças locais, seria mais um exemplo de "imposição" de valores culturais ocidentais, estranhos à cultura e às tradições africanas. Além disso, o reconhecimento do casamento gay criaria um "problema" para as famílias africanas. Vários participantes expressaram sua inquietação em relação a quem seria o responsável por pagar lobola ${ }^{15}$ em uma relação homossexual, já que na cultura africana seria responsabilidade do homem fazê-lo. Na ótica de vários participantes da etnia Zulu, além da questão de quem seria responsável por pagar lobola, haveria o problema de saber como os ancestrais seriam informados de que a sua família está recebendo outro homem para seu filho ao invés de uma makoti. ${ }^{16}$ Para os participantes, isso seria um tabu na cultura Zulu. O dilema ao redor da forma de pagamento de lobola demonstra como um tema de caráter transnacional (como o reconhecimento legal das uniões entre pessoas do mesmo sexo) ganha realces específicos nos diferentes contextos nacionais e culturais (Dehesa, 2010).

A maioria dos grupos religiosos e de lideranças tradicionais sugeriu ao comitê propor uma emenda à constituição de forma a nela constar que o casamento seria apenas a união entre um homem e uma mulher. Também foi amplamente sugerida a realização de referendo nacional a respeito do tema. Dentre os grupos LGBT participantes, foi argumentado que a Civil Union Bill teria sua constitucionalidade questionada na Corte Constitucional, caso aprovada. Para eles, o Parlamento teria duas vias para cumprir o mandato da Corte. Uma delas seria propor uma emenda ao Marriage Act de forma a acrescentar a palavra cônjuge (spouse) no artigo que define o casamento, a fim de incluir os casais do mesmo sexo. Outra via sugerida ao Parlamento seria que ele não tomasse nenhuma decisão e deixasse correr o prazo do dia $1^{\circ}$ de dezembro de 2006, quando a decisão da Corte Constitucional entraria em vigor imediatamente. As audiências públicas foram importante exemplo de empenho do Parlamento sul-africano em possibilitar à população participar do processo de construção da lei. Contudo, vários grupos LGBT criticaram o clima claramente hostil aos homossexuais nas audiências, além da ampla profusão de discursos de ódio contra LGBT.

Uma vez finalizadas as audiências públicas nas províncias, o Comitê Permanente convocou diversas entidades e grupos da sociedade civil a enviarem petições a favor ou contra o projeto de lei no Parlamento. ${ }^{17}$ Desde o início dos debates, ficou clara a polarização entre grupos favoráveis e contrários aos direitos de LGBT. Os opositores concentraram-se especificamente nas associações de cunho religioso. ${ }^{18} \mathrm{~A}$ necessidade de que se mantivesse a instituição do casamento como sendo "entre um homem e uma mu-

15. Lobola significa em tradução livre "o preço da noiva" e consiste no pagamento de uma determinada quantia, normalmente em gado ou o equivalente em moeda corrente, por parte do noivo à família da noiva. Esse costume - ainda presente em diversas famílias de tradição Zulu, Xhosa e Ndebele - visa integrar as duas famílias, promovendo o respeito mútuo e indicando a capacidade do noivo em apoiar sua esposa financeira e emocionalmente.

16. Nora em Zulu.

17. Ao todo participaram vinte entidades, entre elas grupos de defesa dos direitos LGBT, associações e grupos religiosos de diferentes matizes (cristã, islâmica, pagã), universidades e centros de pesquisa, além da Comissão Sul-Africana de Direitos Humanos (SAHRC) e da Comissão de Igualdade de Gênero. Todas as entidades enviaram petições por escrito, com seus argumentos favoráveis ou contrários à lei, juntamente com sugestões e/ ou críticas de como o Parlamento deveria proceder ao reconhecimento legal das uniões entre pessoas do mesmo sexo na África do Sul. Um ou mais representantes de cada entidade fizeram arguições orais e foram questionados pelos membros do comitê acerca de seus posicionamentos.

18. Dentre as entidades que apresentaram petições contrárias ao reconhecimento legal dos casais do mesmo sexo temos: Christian Brethen Church, Christian Lawyers Association, Christian View Network, His People Christian Ministries e Muslim Judicial Comission, 
lher" foi reiterada em diversas passagens das petições. Uma das razões para isso seria a necessidade do Parlamento respeitar as convicções religiosas e morais da maioria dos sul-africanos. Outra razão para manter o casamento como sendo a união entre um homem e uma mulher seria a necessidade de garantir os laços biológicos entre pai, mãe e seus filhos e a estabilidade da própria sociedade. A família heterossexual seria o melhor ambiente para a criação das crianças, já que os casais homossexuais seriam instáveis e infiéis. Garantir a esses casais o reconhecimento do direito a se casarem teria consequências desastrosas, como o aumento no número de divórcios e de crianças criadas fora da instituição do casamento. $\mathrm{O}$ argumento que via a procriação como o fundamento do casamento foi reiterado diversas vezes pelos opositores dos direitos LGBT. Excluir os casais do mesmo sexo seria um exemplo de discriminação justa, ${ }^{19}$ já que esses casais, por não poderem por si só procriarem, estariam fora do âmbito de regulação do casamento.

Ao contrário dos setores opositores aos direitos LGBT - que se concentraram basicamente em entidades de cariz religioso -, dentre as entidades favoráveis ao reconhecimento legal dos casais LGBT, encontramos amplo espectro de organizações, desde grupos de militância LGBT, universidades e centros de pesquisa, as duas entidades defensoras dos direitos humanos e da equidade de gênero, além de associações religiosas. ${ }^{20}$ Dentre essas entidades religiosas, a Igreja Reformada Holandesa (NGK) teve posicionamento peculiar em relação ao tema. Embora defendesse a necessidade de o Estado sul-africano regular as uniões entre pessoas do mesmo sexo, a NGK reservou-se o direito de condenar a homossexualidade, do ponto de vista da moral cristã, e o de não celebrar uniões entre pessoas do mesmo sexo. A entidade enfatizou o caráter laico e secular do Estado sul-africano como condição mesma para o exercício da liberdade religiosa. Seria dever de o Estado legislar para todos e não apenas para um ou mais grupos religiosos. É importante lembrar que essa entidade teve um importante papel na construção, ao longo do século XX, do nacionalismo africâner, uma das principais bases ideológicas do apartheid. ${ }^{21}$

A questão da nomenclatura a ser utilizada para identificar legalmente as uniões entre pessoas do mesmo sexo dominou as discussões no Parlamento. Defensores dos direitos LGBT afirmavam que não aceitariam "nada menos que o casamento". Para eles, a única maneira de promover a equidade plena entre heterossexuais e homossexuais seria alterar a definição presente no Marriage Act de forma a incluir, nesse instituto legal, as uniões celebradas por casais do mesmo sexo. Criar um novo instituto legal seria reproduzir a ideia de que os casais homossexuais seriam inferiores e indignos de fazerem parte da instituição do casamento. Ademais, a constituição sul-africana garante a todos a equidade não apenas do ponto de vista substantivo dos direitos, mas também com relação ao status. A Corte Constitucional frisou que a instituição do casamento garante àqueles que nele celebram sua união uma miríade de direitos, que vão além do âmbito meramente material. Dada a centralidade do casamento na cultura sul-africana, negar aos casais do mesmo sexo o direito de escolha de terem sua união celebrada como "casamento" seria limitar a possibilidade desses casais de serem equiparados, do ponto de vista simbólico, aos seus homônimos heterossexuais. Ao não terem o direito de se casarem, os casais do mesmo sexo seriam privados da possibilidade de celebrar publicamente sua união em um evento reconhecido pela lei. Isso os obrigaria a viver em uma situação de "invisibilidade legal" (legal blankness). ${ }^{22}$

De forma a conciliar os ditames da Corte Constitucional e os interesses de ativistas LGBT e de setores conservadores, a Comissão Permanente propôs substitutivo ao projeto de lei; esse continuou a se denominar Civil Union, mas, diferentemente da versão original, incluía tanto os casais do mesmo sexo quanto os formados por pessoas do sexo oposto. $\mathrm{Na}$ tentativa de solucionar a polêmica sobre como nomear as uniões entre pessoas do mesmo sexo, o substitutivo deixava a critério dos casais a questão de nomear suas uniões como "casamento" ou "parceria civil". Apesar das críticas de ativistas LGBT, o novo projeto manteve a cláusula que previa ao oficial de casamento o direito de se recusar a celebrar uniões entre pessoas do mesmo sexo, alegando questão de "consciência", e a necessidade, por parte dos sacerdotes, da autorização expressa de suas congregações para celebrar uniões de pessoas do mesmo sexo. A despeito da opo-

19. Em seu artigo 36, a constituição sul-africana defende a possibilidade de limitar os direitos previstos na Declaração de Direitos, uma vez que essa limitação seja razoável e justificada em uma sociedade aberta e democrática, baseada na dignidade humana, igualdade e liberdade.

20. É importante frisar que o peso político e simbólico de entidades como a SAHRC, o Conselho de Igrejas da África do Sul (SACC), o Centro de Estudos Legais Aplicados da Universidade de Witwatersrand (CALS) e até mesmo da Igreja Reformada Holandesa (NGK) foi muito importante para a causa do reconhecimento legal das uniões entre pessoas do mesmo sexo.

21. Para uma análise do papel exercido pela NGK na construção do nacionalismo africâner e na fundamentação ideológica do apartheid, vide: RITNER, Susan Rennie, The Dutch Reformed Church and Apartheid, in Journal of Contemporary History, v. 2, n. 4, Church and Politics (Oct., 1967), p. 17-37 e NELSON, Jeniffer, The Role the Dutch Reformed Church Played in the Rise and Fall of Apartheid, in Journal of Hate Studies, v. 2, p. 63, 2003.

22. Paragraph 72, Fourie et al. v. Minister of Home Affairs, CC10/2005. 
sição interna ao projeto no partido governista ANC, a lei acabou sendo aprovada em 30 de novembro de 2006, um dia antes do prazo estipulado pela Corte Constitucional. ${ }^{23}$

É importante frisar que a aprovação de uma nova legislação para regulamentar as uniões entre pessoas do mesmo sexo não necessariamente significa um exemplo de discriminação. Situação semelhante ocorreu em 1998, quando da aprovação da Lei de Reconhecimento do Casamento Costumeiro (Recognition of Customary Marriage Act, 1998). Ao analisar os debates em torno da aprovação da lei, Chambers (2002) identificou proposta inicial de regulação das uniões, defendida pelos líderes tradicionais, que reconhecia um sistema dual (civil e costumeiro) no qual os cônjuges unidos pelo sistema costumeiro estariam sob jurisdição das autoridades africanas tradicionais, que seguiriam a lei convencional para dirimir eventuais conflitos entre os cônjuges. Tal proposta sofreu diversas críticas de liberais e feministas, negras e brancas, por não garantir a igualdade de gênero entre os parceiros de uma união costumeira. ${ }^{24} \mathrm{O}$ Parlamento decidiu, então, por aprovar uma nova lei, que estendia todos os direitos oriundos do casamento previstos no Marriage Act às uniões celebradas pelas leis locais, entre elas a união poligâmica, garantindo a igualdade entre mulheres e homens na relação e a necessidade de consentimento da mulher no caso de seu parceiro optar por realizar uma nova união. Segundo Chambers, a virtude da nova lei estaria no fato de ela reconhecer legalmente a validade dos costumes tradicionais das comunidades negras sul-africanas, ao mesmo tempo em que garantiria os direitos das mulheres nessas uniões.

Segundo ativista LGBT, envolvido nas reivindicações pelo casamento gay, ${ }^{25}$ aprovar uma nova lei seria - no caso específico da regulação das uniões entre pessoas do mesmo sexo - um exemplo de "solução de consenso" que significava ganho para os grupos LGBT, sem necessariamente representar perda para os setores conservadores. Outro ativista ${ }^{26}$ afirmou que, a despeito de toda a polêmica em torno da nomenclatura a ser conferida legalmente aos casais do mesmo sexo, a aprovação do Civil Union Act representou um grande avanço, já que no imaginário social, as uniões entre pessoas do mesmo sexo gozariam do mesmo status das uniões heterossexuais.
Outra consequência inesperada desse "compromisso" foi que a lei acabou possibilitando, tanto aos casais homossexuais como heterossexuais, definir como desejam nomear suas uniões. O Civil Union Act previu duas formas de relação conjugal - casamento e parceria civil - que possuem o mesmo efeito legal. Assim, embora irrelevante do ponto de vista legal, o Civil Union Act proporcionou aos casais a oportunidade de decidir sobre o significado pessoal e social que eles desejariam atribuir às suas relações. Se intencionalmente ou não, a lei, ao criar uma alternativa com os mesmos direitos ao casamento, de alguma forma descentralizou o casamento como "a" instituição conjugal por excelência. Nesse sentido, o Civil Union Act seria a base para uma nova lei de família mais inclusiva e diversa (Bilchitz e Judge, 2008).

\section{Considerações finais}

A reivindicação pelo reconhecimento legal das uniões entre pessoas do mesmo sexo na África do Sul insere-se em um contexto mais amplo da luta pelo direito à livre orientação sexual. Desde meados da década de 1980, ativistas gays e lésbicas sul-africanos têm afirmado a garantia de direitos a gays e lésbicas, como parte da luta geral pelos direitos humanos, logrando a inclusão da proibição de discriminação por orientação sexual na primeira constituição democrática do país. Uma vez previsto na versão final da constituição promulgada em 1996, o direito à livre orientação sexual foi utilizado por ativistas gays e lésbicas para revogar leis e estatutos que criminalizavam as relações sexuais consensuais entre adultos do mesmo sexo e estender aos casais homossexuais os direitos referentes à sociedade conjugal, no que ficou conhecido como a estratégia "lista de compras". Tal estratégia foi viável em virtude da tradição consuetudinária da Common Law do direito sul-africano, na qual as decisões favoráveis a respeito de um tema são vinculantes para outros casos semelhantes. O protagonismo da NCGLE nas ações de lobby junto ao Parlamento e à Corte Constitucional também foi fundamental para a implementação dessa estratégia e para o sucesso da construção dos direitos sexuais de gays e lésbicas no país. A demanda pelo casamento gay já fazia parte da agenda de reivindicações da militância

23. O secretário-geral do Congresso dos Líderes Tradicionais da África do Sul (CONTRALESA), Mwelo Nkonyana, e o presidente da organização, Patekile Holomisa, membros do ANC, conclamaram a liderança do partido a "liberar" a bancada para votar de acordo com a consciência individual. No entanto, o Comitê Executivo Nacional (NEC) reafirmou o compromisso do ANC com a Constituição e fechou questão no tema, "instruindo" a todos os membros do partido participarem da votação e apoiarem a aprovação da lei, sob pena de processo disciplinar. O peso do ANC no Parlamento foi decisivo na aprovação, já que o partido detinha mais de 60\% das cadeiras do Parlamento à época.

24. Na lei costumeira tradicional, reconhecida pelas autoridades coloniais, e durante o apartheid, as mulheres encontravam-se em posição subordinada em relação a seus parceiros, não podendo, por exemplo, dispor de seus bens no caso de morte de seu companheiro.

25. Entrevista Paul, 20.10.2009

26. Entrevista Charles, 2.12.2009 
LGBT. Porém, em virtude do diagnóstico desfavorável da conjuntura política nacional e da constatação dos altos índices de homofobia na sociedade, a NCGLE decidiu por não trazer a causa do casamento gay, vista como potencialmente polêmica para a opinião pública sul-africana. Seguindo os princípios estabelecidos pela estratégia "lista de compra", a questão do casamento surgiria naturalmente das diversas vitórias acumuladas nos tribunais.

A trajetória de reivindicação pelo reconhecimento legal dos casais do mesmo sexo não seguiu o caminho previsto por ativistas LGBT, quando dos debates pela aprovação do Civil Union Act no Parlamento. Ao invés de alterar a definição de casamento presente no Marriage Act, desejada pelos defensores dos direitos LGBT e rejeitada pelos seus opositores, o Parlamento optou por uma solução de consenso: aprovar uma lei distinta, aberta tanto a casais do mesmo sexo quanto a casais de sexo diferente, deixando a questão da definição de como nomear essas uniões (parceria civil ou casamento) a cargo dos indivíduos contratantes.

\section{Referências}

BBC NEWS. Uganda MP urges death for gay sex. In: BBC News, 15 set. 2009. Disponível em: http://news.bbc. co.uk/go/pr/fr/-/1/hi/world/africa/8308912.stm. Acesso em: 15 nov. 2011.

BERGER, Jonathan. Getting to the Constitutional Court on time: a litigation history of same-sex marriage. In: JUDGE, Melanie; MANION, Anthony; DE WAAL, Shaun (Ed.).To have $\&$ to hold: the making of same-sex marriage in South Africa. Johannesburg: Fanele, 2008.

BILCHITZ, David; JUDGE, Melanie. The Civil Union Act: messy compromise or giant leap forward? In: JUDGE, Melanie; MANION, Anthony; DE WAAL, Shaun (Ed.). To have \& to hold: the making of same-sex marriage in South Africa. Johannesburg: Fanele, 2008.

BUTLER, Judith. O parentesco é sempre tido como heterossexual? In: Cadernos Pagu, n.21, 2003.

CHAMBERS, David L. Civilizing the natives: customary marriage in post-apartheid South Africa. In: SHWEDER, Richard; MINOW, Martha; MARKUS, Hazel Rose (Ed.). Engaging cultural differences: the multicultural challenge in liberal democracies. New York: Russell Sage Foundation, 2002.

CHAUNCEY, George. Why marriage? The history shaping of today's debate over gay equality. Cambridge: Basic Books, 2004.

CROUCHER, Sheila. South Africa's democratization and the politics of gay liberation. In: Journal of Southern African Studies, v. 28, n. 2, 2002.

DEHESA, Rafael de la. Queering the public sphere in Mexico and Brazil: sexual rights movements in emerging
Do ponto de vista simbólico, a criação de uma lei distinta não necessariamente significou a reprodução do princípio de "iguais, mas separados". Com a aprovação do Civil Union Act, todos os direitos referentes ao casamento foram estendidos aos casais do mesmo sexo. Da mesma forma, a aprovação da lei representou grande avanço nos direitos sexuais de gays e lésbicas, já que no imaginário social sul-africano, a despeito das diferenças de caráter formal, as uniões entre pessoas do mesmo sexo gozariam do mesmo status do casamento heterossexual. Apesar desses importantes avanços, a lei aprovada peca por manter a possibilidade de recusa, por parte dos oficiais de casamento, em celebrar uniões entre pessoas do mesmo sexo sob alegação de "razão de consciência", e a necessidade, por parte dos sacerdotes, da autorização expressa de suas congregações para celebrar uniões de pessoas do mesmo sexo. Tais previsões legais constituem empecilhos que devem ser removidos para a consolidação de uma legislação de família plenamente democrática e inclusiva na África do Sul.

democracies. Durham/London: Duke University Press, 2010.

ENGEL, Stephen M. The unfinished revolution: social movement theory and the Gay and Lesbian Movement. Cambridge: Cambridge University Press, 2001.

FASSIN, Eric. Same sex, different politics: "gay marriage" debates in France and the United States. In: Public Culture, v. 13, n. 2, 2001.

FINE, Derrick; NICOL, Julie. The lavender lobby: working for lesbian and gay rights within the liberation movement. In: CAMERON, Edwin; GEVISSER, Mark (Ed.). Defiant desire: gay and lesbian lives in South Africa. New York: Routledge, 1995.

GEVISSER, Mark. A different fight for freedom: a history of South African lesbian and gay organization from the 1950s to the 1990s. In: CAMERON, Edwin; GEVISSER, Mark (Ed.). Defiant desire: gay and lesbian lives in South Africa. New York: Routledge, 1995.

GUILIOMEE, Hermann; MBENGA, Bernard. New history of South Africa. Cape Town: Tafelberg, 2007.

HOAD, Neville; MARTIN, Karen; REID, Graeme (Ed.). Sex E politics in South Africa. Cape Town: Double Storey Books, 2005.

KITZINGER, Celia; WILKINSON, Sue. The rebranding of marriage: why we got married instead of registering a civil partnership. In: Feminism \& Psychology, v. 14, n. 1, 2004.

LONG, Scott. More than a name: State-sponsored homophobia and its consequences in Southern Africa. New York: Human Rights Watch and the International 
Gay and Lesbian Human Rights Commission, 2003. LOUW, Ronald. Advancing human rights through constitutional protection for gays and lesbians in South Africa. In: Journal of homosexuality, v. 48, n. 3/4, 2005.

MACRAE, Edward. A construção da igualdade: identidade sexual e política no Brasil da "abertura". Campinas:
Editora da Unicamp, 1990.

PHILLIPS, Oliver. Zimbabwean law and the production of a white man's disease. In: Social and legal studies, v. 6, n. 4, 1997.

THOMPSON, Leonard. A history of South Africa. New Haven: Yale University Press, 2001.

\title{
Citizenship and sexual rights in South Africa: considerations on the legal recognition of same-sex unions
}

\begin{abstract}
This article analyses the path towards the construction of sexual rights related to same-sex conjugality in South Africa. Based on findings of the $\mathrm{PhD}$ research entitled "Citizenship and sexual rights: a comparative study on the legal recognition of same-sex unions in Brazil and South Africa", the paper addresses the way lesbian and gay activists have idealized and implemented the struggle to the legal recognition of same-sex couples in that country. The social and political context in South Africa will be discussed, with special emphasis on the transitional period to black majority rule. The strategies of action used by gays and lesbian activists and their main antagonists will also be scrutinized, together with the (un)intended results of their mobilizations in legal terms.
\end{abstract}

Key-words: citizenship, sexual rights, same-sex unions, legal recognition, South Africa.

\section{Ciudadanía y derechos sexuales en Sudáfrica: reflexiones sobre el reconocimiento legal de las uniones entre personas de mismo sexo}

\section{Resumen}

\begin{abstract}
El texto analiza la trayectoria de construcción de los derechos sexuales relativos a la conyugalidad de parejas del mismo sexo en Sudáfrica. Basado en los resultados de la investigación de doctorado Ciudadanía y derechos sexuales: un estudio comparativo del reconocimiento legal de las uniones entre personas de mismo sexo en Brasil y Sudáfrica, el artículo es una reflexión sobre la forma como activistas gays y lesbianas idealizaran y pusieran en práctica la lucha por el reconocimiento legal de las parejas de mismo sexo en aquel país. El contexto social y político del país, con especial énfasis en el período de transición hacia el gobierno de mayoría negra, será discutido, juntamente con el análisis de las estrategias de acción de activistas gays y lesbianas, sus principales opositores y los resultados, intencionales o no, de sus movilizaciones en términos de logros legales.
\end{abstract}

Palabras-clave: ciudadanía, derechos sexuales, uniones entre personas de mismo sexo, reconocimiento legal, Sudáfrica.

Data de recebimento do artigo: 18/04/2012

Data de aprovação do artigo: 20/07/2012 